\title{
Electromagnetic Spider Web Placement in the Southeast Coastal Seismic Belt in China
}

\author{
Min Jiang \\ Ningbo Polytechnic, Ningbo, China \\ Email: chiangm@163.com
}

How to cite this paper: Jiang, M. (2017) Electromagnetic Spider Web Placement in the Southeast Coastal Seismic Belt in China. Open Access Library Journal, 4: e3351. https://doi.org/10.4236/oalib.1103351

Received: January 3, 2017

Accepted: February 5, 2017

Published: February 8, 2017

Copyright ( 92017 by author and Open Access Library Inc.

This work is licensed under the Creative Commons Attribution International License (CC BY 4.0).

http://creativecommons.org/licenses/by/4.0/

\section{(c) (i) Open Access}

\begin{abstract}
The electromagnetic spider webs will be placed in the southeast coastal seismic belt. Instrument every year to replace the battery life can reach 20 years. After the instrument is placed, each group can absorb the anomaly of the earth's electromagnetic field about 30 square kilometers. In each device, an electronic compass with a set of magnetic anomalies is detected. Using a special timer, opening 4 times per minute, the opening time is about 5 - 15 seconds. We found it is abnormal after repeated scanning electric signal through the GPRS network to judge, in a few days before the earthquake can know the earthquake abnormal electromagnetic field signal strength. The focus is on the use of ten kinds of ancient China tactics, further analysis of the quake epicenter. The equipment has low cost and low power consumption, so it is a good short impending earthquake prediction method [1] [2] [3].
\end{abstract}

\section{Subject Areas}

Environmental Sciences

\section{Keywords}

Earthquake Prediction, The Southeast Coastal Seismic Belt, Magnetic Switch Module, Wireless Transmitting and Receiving Module, GPRS Network Spider Nets, Electromagnetic Spider Web, Google Earth

\section{Introduction}

Based on the analysis of Google map, the trend of the intensity of seismic intensity on the southeast coast and the weak intensity of the northern part of the earthquake are related to the strain field and the transverse direction. The increasing degree of earthquake along the southeast coast as well as strong earthquakes in the South and weak earthquakes in the North have something to do 
with the strain field and the transverse strike-slip: As the stress strain field in regions on the south of the fracture zone experiences greater changes than regions on the north multiple complicated and lower-degree couplings, the creep deformation is thus created to generate stress blocking and cause earthquakes. East Fujian has a crustal homogeneity that's weaker than the Taiwan Strait, and a geophysical field that's more changeable, which makes for a more complex multiplex and multi-field coupling. The coupling field is less stable and is easily interfered by the lateral tectonic activities, which will cause an elastic deformation and potentially lead to a stronger earthquake. A large number of devices can easily measure the location of the epicenter. This equipment has been successfully manufactured with low cost and low power consumption for outdoor installation equipment, and $5 \#$ battery can be used for 2 years, and is a good method to predict the short-term earthquake [4] [5].

\section{Southeast Coastal Seismic Belt Geographic Information}

Figure 1 shows the southeast coastal seismic belt will place electromagnetic spider web. The seismic activity in the southeast coastal region is mainly distributed in the north coast, south of Zhejiang, South to Guangdong and the Leiqiong area of Guangxi, including Fujian, Guangdong and throughout southern Jiangxi, forming a roughly parallel to the coastline of the relatively narrow earthquake zone, known as the southeast coastal seismic belt. It is one of the seismic activity belts in China. Based on the analysis of the characteristics and causes of some tectonic stress fields in the southeast coast and adjacent areas and the results of a large number of focal mechanism characteristics are obtained, it is agreed that: the tectonic stress field principal compressive stress axis has the characteristics of the sector distribution. The principal compressive stress axis orientation force is evident from the east to the west gradually by the near east to change south east to and from north to south, as a fan open fold into an obtuse angle shape, called "fan-shaped distribution" [6] [7].

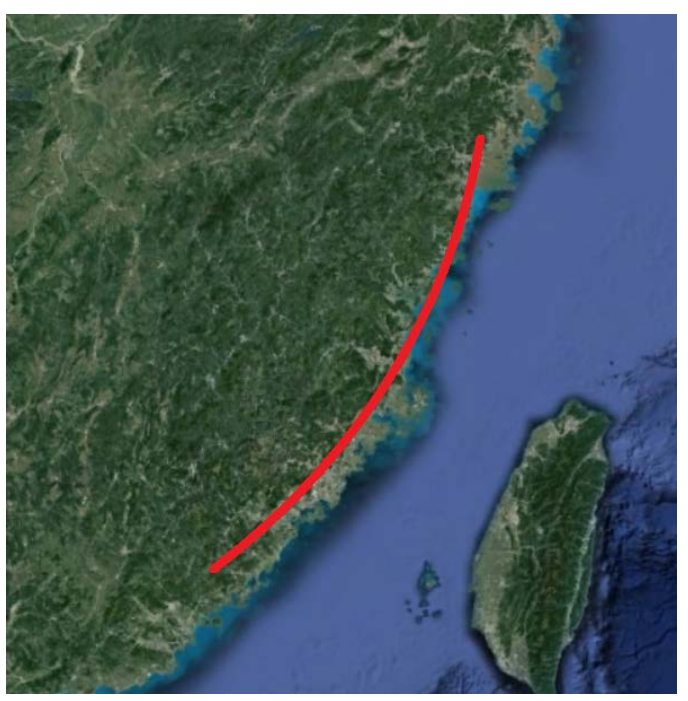

Figure 1. The Southeast coastal seismic belt. 


\section{Google Earth}

Google earth as an auxiliary means is completely possible to find places to place. Looking for points in the early days is also very practical to reduce the manpower. It is very difficult to find the abnormal electromagnetic point by using the usual method, such as looking for a needle in the ocean. It is not easy to measure to explore on foot. Relying on "Google earth" can be easily found in geological anomalies. In order to reduce the cost of placement, usually rely on Google earth to find latitude and longitude, and then use the mobile phone to find the corresponding location on the map search, recording $\mathrm{E}$ latitude and $\mathrm{N}$ longitude can be a decimal system, and can also be a binary. This is the scientific development of productive forces.

\section{The Method Used to Determine the Location of the Epicenter}

Figure 2 shows the place of electromagnetic spider web on single-line battle array. A plurality of electromagnetic spider nets is connected into groups in a straight line shape. Single-line battle array is a kind of war array. According to the habits of snakes and deduction, soldiers are arranged in a strip head and tail into the array liner three. Hydra array, like Pythons eat cattle, is very powerful. The two wings of the cavalry (ancient maneuverability arms) maneuvering ability are the most important, so to get rid of a snake, the best way is to limit the wings of mobility, and in the end cannot change.

Figure 3 shows the place of electromagnetic spider web on two dragon water outlet array. A plurality of electromagnetic spider nets is divided into two paths and is connected into groups in a straight line shape. Electromagnetic spider webs are divided in two like two dragons. There are two hidden dragon array and the Dragon belongs to Yang; the water belongs to Yin; the dragon is in the water; everything is safe. After leaving water the two dragons are more powerful and unstoppable.

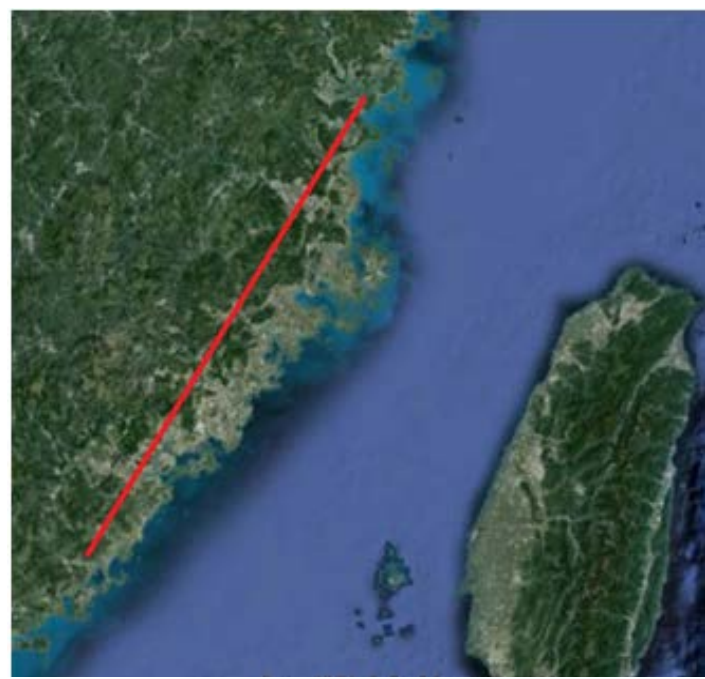

Figure 2. Single-line battle array. 
Figure 4 shows the place of electromagnetic spider web on Heaven and earth powers array. A plurality of electromagnetic spider nets are divided into three groups, each of which is connected into a group of three groups in a straight line shape, and the epicenter position is detected. Two sides and one center to formation of three long forward forms called heaven and earth powers array.

Figure 5 shows the place of electromagnetic spider web on the four gate fallback array. Multiple electromagnetic spider network soldiers are divided into four roads, from beginning to end respectively with a straight line shape into a rectangular group, detection epicenter location. The number of "four" is not popular with the public in China. The reason is "four" and "death" is a homonym, in Chinese. Chinese people have always been very taboo for "death", and it will produce what "death" and "Xian", "riding a crane" to "death" also ashamed to say the way of expression. People don't like the number 4 when choosing a mobile phone number. In fact, four electromagnetic spider webs can be mutual reference such as four seasons in a year contain a life cycle: spring, summer, autumn and winter.

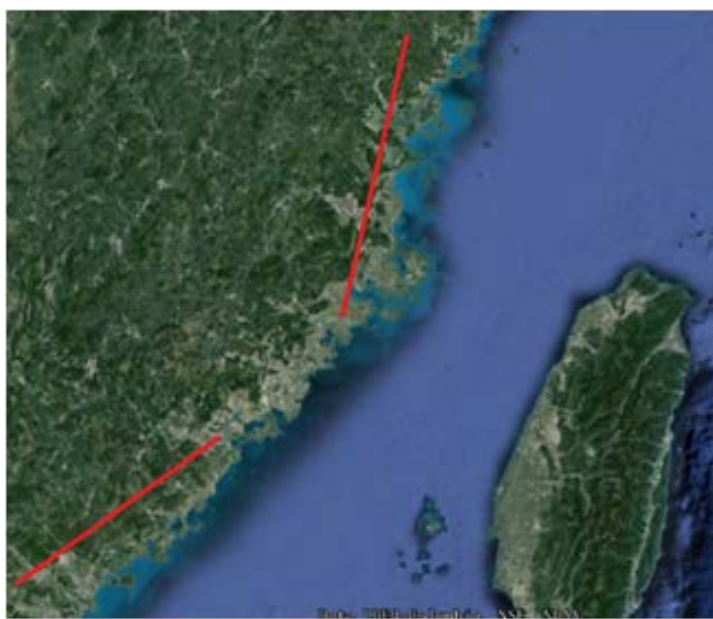

Figure 3. Two dragon water outlet array.

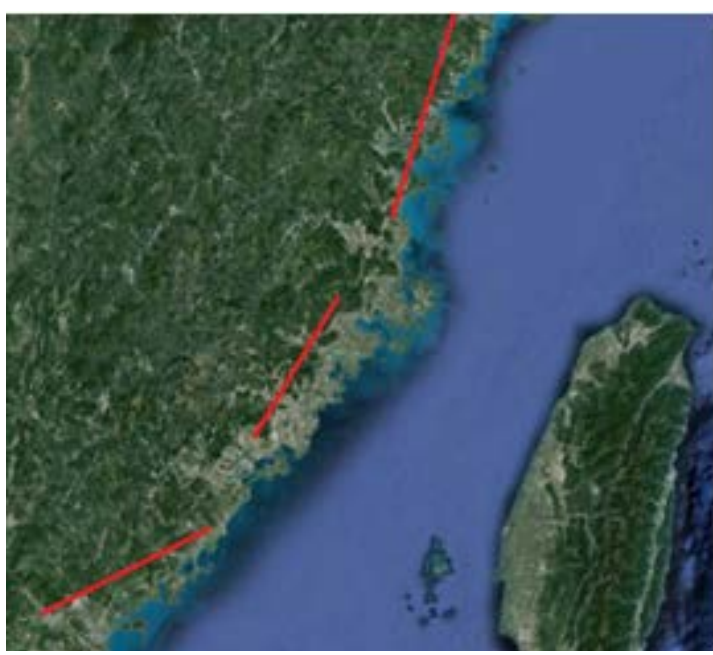

Figure 4. Heaven and earth powers array. 
Figure 6 shows the place of electromagnetic spider web on five tigers and large group of sheep. Multiple electromagnetic spider network soldiers are divided into five roads, from beginning to end respectively with a straight line shape into $\mathrm{V}$ type group, detection epicenter location. Five tigers and large group of sheep array deal with the main enemy of psychological front equipment according to $\mathrm{V}$ written words arranged in the team with the same type of symbol of victory.

Figure 7 shows the place of electromagnetic spider web on six butyl arrays. Multiple electromagnetic spider network soldiers are divided into six Yang Road, six Yin Road, from beginning to end respectively in a straight line shape into the Israeli flag type group, detection epicenter location. For God and the six butyl butyl Malacca God collectively, the God twelve, one said they were initially Tati's Ministry, and six butyl temple is the sixty meridians in "butyl" and "six" the temple of god. Yin and Yang is a kind of mutual protection and is equivalent

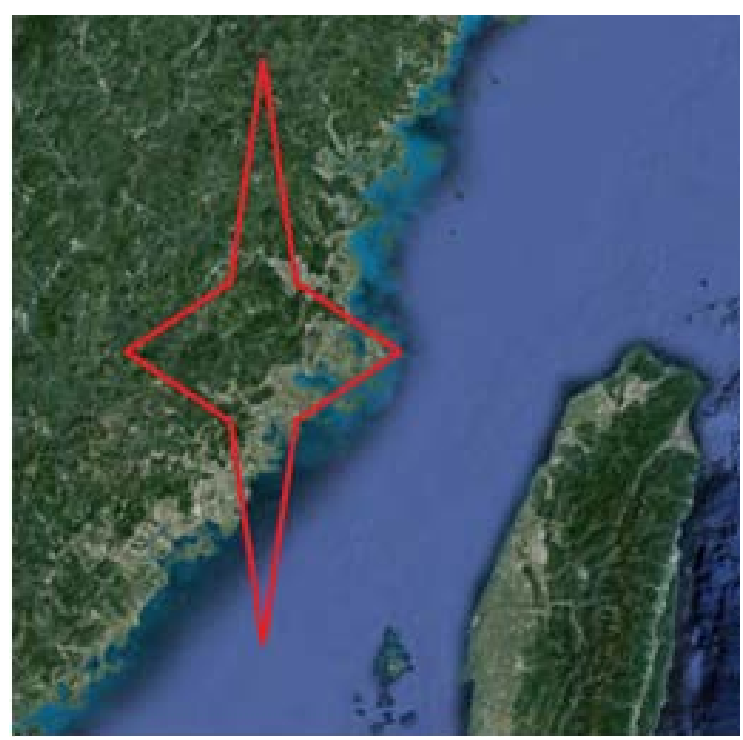

Figure 5. Four doors reveal all the details array.

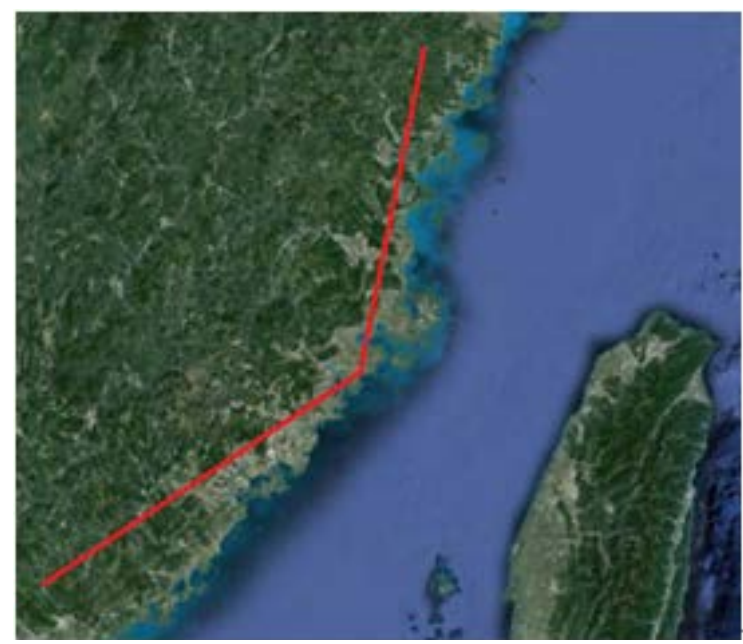

Figure 6. Five tigers and large group of sheep. 
to the protection of meaning. Butyl is the goddess. The six butyl is a legendary Taoist God Dharma's Malacca is God; is Tati men, "praying spirits", also called: "electromagnetic find ghost".

Figure 8 shows the place of electromagnetic spider web on Big Dipper array. Multiple electromagnetic spider network soldiers are divided into seven points, from the beginning to the end of each with a straight line shape into the "Big Dipper" type group, detection epicenter location. Big Dipper: seven is the six electromagnetic cobwebs in two upside down and overlapping equilateral triangle to put, the specific length of electromagnetic spider web is a multiple of seven, the central put a larger electromagnetic spider web and a star, this is known as the seven array. It is said that the electromagnetic spider web placed into a star type has a powerful energy, the star array, and its energy is more powerful.

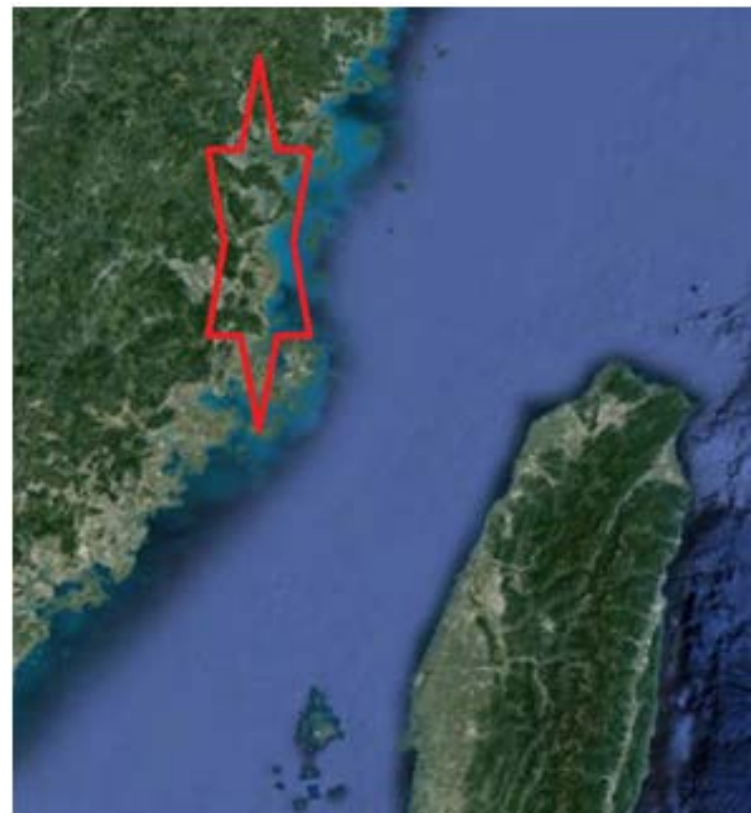

Figure 7. Six butyl array.

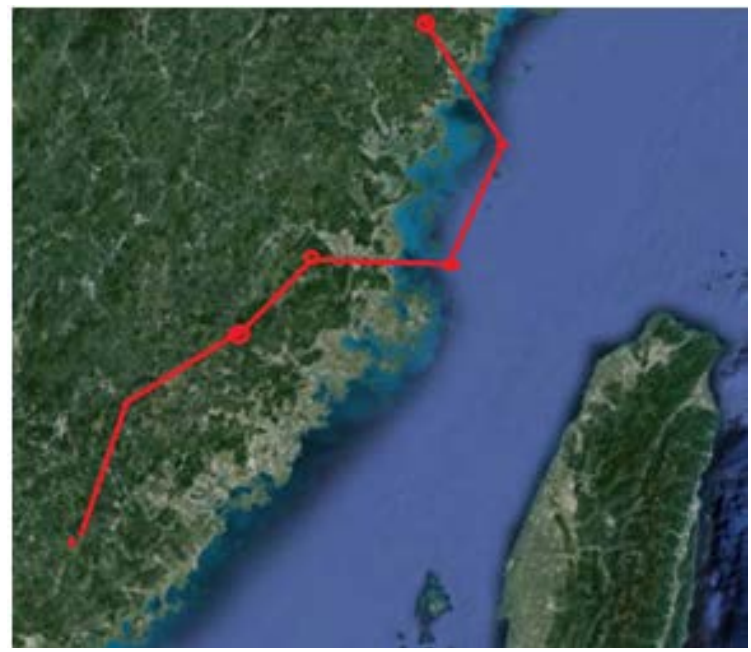

Figure 8. Big dipper array. 
Seven Star array can gather energy, and will play to the limit of the magnetic field. Different types of the star composition of different types of the star seven array, such as white the star seven array can help protect the home from evil, scattered negative energy, enhance spirituality, peace of mind.

Figure 9 shows the place of electromagnetic spider web on eight golden arrays. "Eight Golden arrays" is based on "numerology" in the eight ranges, astrology, topography and other factors for the development of the ancient battlefield of the war. Electromagnetic spider webs divided eight sets in the clockwise placement.

Figure 10 shows the place of electromagnetic spider web on nine character array. Multiple electromagnetic spider webs are divided into nine. The nine webs from beginning to end are respectively with a farmland line shape into a nine character array detection epicenter location.

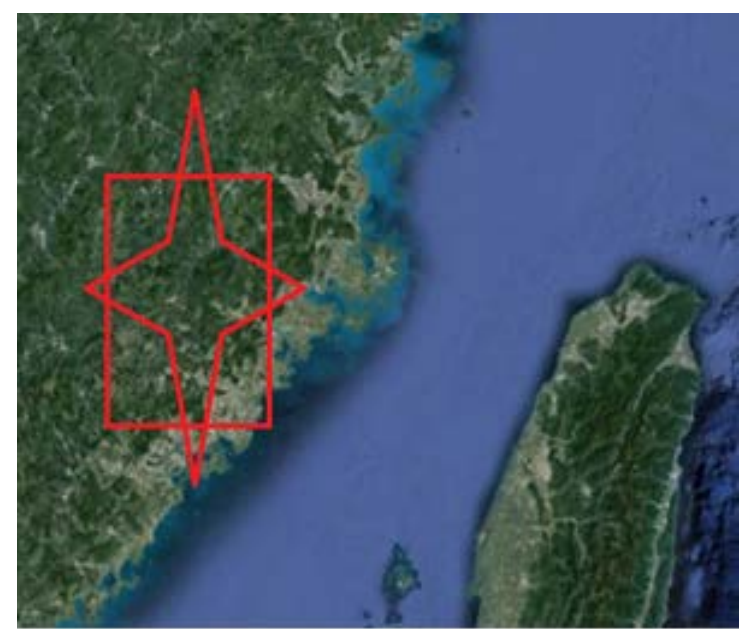

Figure 9. Eight golden array.

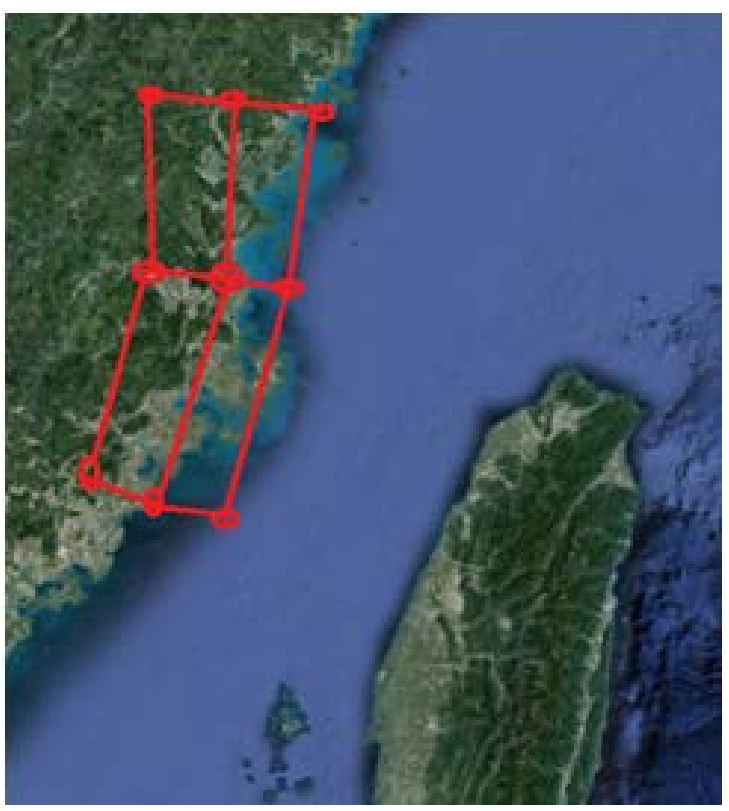

Figure 10. New word serial array. 


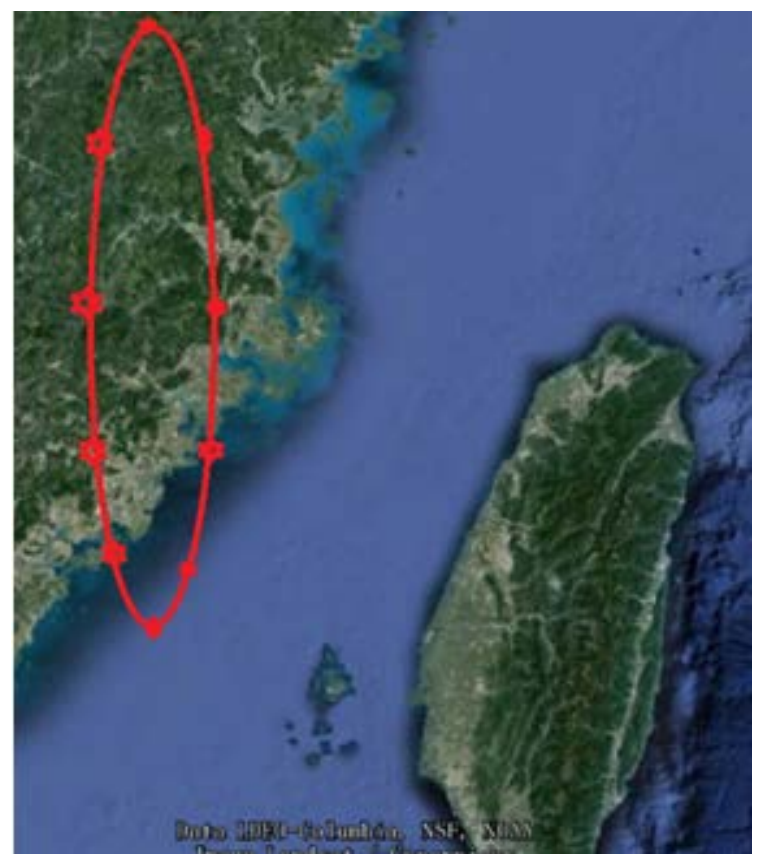

Figure 11. Ten part ambush array.

Figure 11 shows the place of electromagnetic spider web on ten part of the ambush array. This is one of the ten ancient arrays. A plurality of electromagnetic webs formed into ten ambush arrays. Lure abnormal electromagnetic fields into the specified scene according to one day whenever and wherever possible to set this method has no fixed pattern. This can help to find abnormal of the ambush mountain valley and other special terrain, the enemy (abnormal electromagnetic signal) into the specified array ambush scene. There is one of the most comprehensive and best methods to detect an earthquake center.

\section{Conclusion}

The southeastern coastal seismic belt mainly includes a small part of two provinces: Fujian, Guangdong, and Jiangxi, Guangxi. This seismic belt is controlled by NE trending active faults controlled by the parallel coastline. In addition, some NW active faults also play a role in forming seismogenic conditions. Several destructive earthquakes occurred along the fault zone. Placing electromagnetic spider webs in southeast coastal seismic fault is of practical significance to protect state property. Unicom, mobile coverage to the region can easily grasp the electromagnetic information. Abnormal electromagnetic changes can be seen at a glance. Every time you put the instrument, firstly, you open the mobile data or WIFI positioning and then the phone into the $3 \mathrm{D}$ mode, and click the Google earth GPS Icon. It has great significance to find the epicenter position with ten ancient Chinese tactics and to deal with the electromagnetic anomalies before the earthquake [8] [9].

\section{References}

[1] Jiang, M. (1992) Multi Point Timing Control Circuit. Electric World, No. 4, 42. 
[2] Jiang, M. (1996) Sound and Light Indicator of Electronic Compass. Electric World, No. 2, 33.

[3] Jiang, M. (2010) Earthquake Prediction Micro Integrated Measurement Recorder. Technology Innovation Herald, No. 29, 22-23.

[4] Du, J. and Ma, J.X. (2012) Analysis of Earthquake Optimization Mimesis before Yushu Ms 7.1 Earthquake. Seismological and Geomagnetic Observation and Research, 33, 15-20.

[5] Jiang, M. (2014) Electromagnetic Spider Web Application in Earthquake Prediction. International Core Journal of Scientific Research \& Engineering Index, 1, 111-114.

[6] Li, X.J., Li, D.S., Mao, G.L. and Chang, L. (2012) Remote Monitor and Control System for Seismic Station Based on MCU. Seismological and Geomagnetic Observation and Research, 33, 84-87.

[7] Li, X.L., Zhang, L., Dong, X.N. and Lin, M. (2016) The Data Tracking and Analysis of Earthquake Precursor Networks in Shandong Province. Seismological and Geomagnetic Observation and Research, 37, 142-146.

[8] Jiang, M. (2016) Application of 3 Kinds of Practical Electromagnetic Spiders in Electromagnetic Spider Web. ICEICE 2016 02083. MATEC Web of Conferences 44.

[9] Jiang, M. (2016) Easily Magnetic Anomalies Earthquake Prediction. International Conference on Mechatronics, Manufacturing and Materials Engineering, 63, 1-5.

https://doi.org/10.1051/matecconf/20166301020

Submit or recommend next manuscript to OALib Journal and we will provide best service for you:

- Publication frequency: Monthly

- 9 subject areas of science, technology and medicine

- Fair and rigorous peer-review system

- Fast publication process

- Article promotion in various social networking sites (LinkedIn, Facebook, Twitter, etc.)

- Maximum dissemination of your research work

Submit Your Paper Online: Click Here to Submit

Or Contact service@oalib.com 